\title{
LAS PROPUESTAS DE IAN HACKING Y JUDITH BUTLER SOBRE LO SOCIALMENTE CONSTRUÍDO. EL CASO DE LA “JUVENTUD” EN LA MIRADA SOCIOLÓGICA
}

\author{
Gastón Becerra \\ Universidad de Buenos Aires
}

\begin{abstract}
Resumen: Se presentan las propuesta de lan Hacking y Judith Butler en torno al carácter construido de las clasificaciones sociales y su relación con los sujetos sociales que las componen, así como también la dinámica de construcción de las mismas en clave critica. Los lineamientos epistemológicos relevados sobre el construccionismo en ciencias sociales son utilizados para explorar los consensos básicos de los estudios sociológicos en torno a la categoría de "juventud". Hacía el final del artículo y a modo de excurso se proponen algunas líneas de estudio para el construccionismo social en clave de la teoría general de sistemas sociales de Nikas Luhmann.
\end{abstract}

Palabras c lave: lan Hacking, Judith Butler, construccionismo y constructivismo social, Niklas Luhmann, sociología de la juventud

\section{On I an Hacki ng's and Judith But ler's social construct ivism. The case of "youth" in the sociological studies}

\begin{abstract}
The purpose of this paper is to present Judith Butler's and lan Hacking's considerations in relation to the constructed nature of social classifications and their relationship with the social subjects that are classificated, as well as the dynamics of these constructions in a critical key. These author's epistemological guidelines are used to explore the basic consensus in sociological studies about the category of "youth". Towards the end of the document -as an excursus- a few exploration guidelines are proposed connecting lan Hacking and Niklas Luhmann.
\end{abstract}

Keywords: Ian Hacking, Judith Butler, constructuvism \& social constructions, Niklas Luhmann, sociology of youth

\section{Introducción}

Al acercanos al enfoque constructivista o construccionista en ciencias sociales constatamos la convivencia de varias posturas heterogéneas cuyo matices se enfrentan en lo epistemológico, metodológico y teórico (Retamozo, 2011). Sin embargo, Nightindale y Cromby (1999:3-6) destacan cuatro aspectos "positivos" que nuclean a los construccionistas: la primacía por los procesos sociales (más que la centralidad de los productos), la especificidad de lo histórico y cultural, el conocimiento ligado a la acción y a los propósitos, y finalmente, apertura a una postura crítica. Los cuatro aspectos son centrales en la obra de los filósofos que 
indagaremos en el presente trabajo y a quienes podemos ubicar en el mapa del constructivismo siguiendo la huella de los trabajos arqueológicos de Foucault: el canadiense lan Hacking y la norteamericana Judith Butler. Ambos autores han trabajado en sus campos con la construcción social de distintos fenómenos a la vez que comprometidos por prácticas emancipatorias (por ejemplo, enfermedades mentales en el caso de Hacking; identidades y prácticas sexuales en el caso de Butler) a la vez que han profundizado el debate epistemológico en torno a la posición constructivista. Éstos últimos aportes son relevados en el presente trabajo a fin usarlos como criterios de análisis con respecto al estado del arte de la sociología de la juventud.

\section{La propuesta de lan Hacking para el construccionismo social}

Con el término de "construcciones sociales", el filósofo canadiense lan Hacking se refiere a ciertos tipos de clasificaciones y agrupamientos que se aplican sobre sujetos, objetos y experiencias. Su análisis parte de detectar discursos sociales que den por supuesto o inevitable a una de estas clasificaciones. Su crítica consiste en desenmascarar que dicha clasificación es contingente y producto de una historia social, y en la especificidad en cómo las mismas interactúan con la realidad social.

Al centrarse en las clasificaciones como lo socialmente construído, Hacking trata primariamente con un objeto de corte epistemológico: las ideas. Cabe aclarar que si bien las ideas son constructos abstractos, sus extensiones son objetos en el mundo. La ontología de Hacking divide así: ideas (conceptos, clasificaciones, agrupamientos, clases, creencias), objetos (personas, experiencias, acciones, relaciones, elementos observables e inobservables - e incluso entidades ontológicamente subjetivos y epistemológicamente objetivos) y "palabras ascensor" (metalenguaje utilizado para referirnos a lo que conocemos del mundo, como "verdad", "hechos", "realidad"). Las ideas no se dan en el vacío (lo que ubicaría a Hacking en la línea del nominalismo puro) sino que se gestan y desarrollan en "matrices", marcos sociales en las que se debaten y se enfrentan con otras ideas: instituciones, simbologías, prácticas profesionales, infraestructuras, es decir, en el plano de la "cruda materialidad".

Veamos el esquema de Hacking en un primer ejemplo: Ana es una muchacha que atraviesa la adolescencia. Se espera que Ana, como una "joven sana", tenga expectativas claras tendientes a la maternidad y a la formación de una familia (en oposición a una sexualidad activa no vinculada a la procreación). Ana es un producto de su historia personal y familiar, así como de la interacción entre la cultura de su tiempo, sus condicionantes sociales y sus decisiones personales; ningún construccionista (tampoco Hacking) diría que Ana es una "construcción", o en última instancia, dirán que Ana -en tanto persona concreta- sería una "construcción indirecta". Por otro lado, la categoría de "joven sana" a la que Ana se ve sujeta es plausible a la crítica construccionista, en los términos de Hacking (2001;26-35,48-57) porque: 
a. es un discurso que en cierto contexto social se da por supuesto o inevitable [cabe constatar la obviedad de que las categorías funcionan en términos de "expectativas" y que las mismas siempre son supuestas, es decir, dichos discursos son relativo al sentido común y como tal -en clave de Laclau- plausibles al análisis de hegemonía], escondiendo su carácter contingente,

b. ya que no está "determinado por la naturaleza" [que Ana debiera comportarse como una "joven sana" (se entiende que tal discurso se fundamenta en un "esencialismo" de la juventud y de la mujer que propone categorías universales basadas en su desarrollo fisiológico)],

c. por eso tal discurso es "bastante malo" [o al menos podríamos decir que al imponer un estilo de vida a Ana cohibe sus opciones en tanto "agente moral"],

d. por lo tanto sería deseable que dicha construcción fuese eliminada o modificada radicalmente.

La construcción de la "joven sana" en tanto una persona que debe mantener bajo control sus impulsos sexuales no es una idea generada en abstracto sino que responde a la escuela de pensamiento psicológico de Ana Freud (Alpízar, Bernal, 2003:4) que podríamos suponer que tiene fuertes ecos en una sociedad en la que pesan la diferenciación de géneros y los roles tradicionales de la familia nuclear. Dicho ámbito social y científico (con sus institutos, sus profesionales, sus teorías divulgadas en la sociedad, sus símbolos culturales...) serían parte de la matriz que gestan la idea/clasificación de la "joven sana".

La clasificación no queda en el mundo de las ideas sino que opera sobre el clasificado, reificándose. Volviendo a nuestro ejemplo: Ana, en tanto sujeto a la que se interpela con la categoria de joven con una normativa de género, se verá ella misma construida en tanto esa joven ideal. Quienes pongan en marcha dicha construcción serán los agentes del aparato biomédico que conforman la matriz originaria de dicha clasificación (por medio de sus recursos institucionales u operaciones menos sutiles como la coacción y el disciplinamiento) y otros agentes sociales que se hace eco de dicho discurso (por medio de pautas culturales divulgadas a la sociedad). Sin embargo, Ana -por su parte- puede anticipar el comportamiento que se espera de ella, tanto a fin de acatarlo y evitar un tratamiento correctivo como para oponerse acentuando un comportamiento disruptivo, forzando los límites de la clasificación, o tomando acciones culturales y políticas en contra de la misma.

Así también los sujetos clasificados interactúan con la clasificación en una relación de influencia hacia ambos lados (y no sólo de ciertos sectores "de poder" hacia la clasificación). El actor en Hacking es capaz de "tomar control sobre el propio destino apropiandose de las categorías mismas que se les aplican" (2001:103). Hacking denomina a dichos fenómenos, propios de las ciencias humanas, "clases interactivas".

Su postura (en éste trabajo y en aquellos que comprenden a su obra desde mediados de los '90) se inscribe en el "nominalismo dinámico". Ubicarnos en dicha corriente nos obliga a comenzar por una breve distinción de las las posiciones del realismo / nominalismo (previa aclaración de que ambas corrientes 
comprenden en su interior un abanico de posiciones y versiones). La postura realista sostiene que hay una existencia de los fenómenos y las cosas independientes de nuestro modo de conocerlas. En lo que respecta a las clasificaciones, los géneros y especies, ésta consistiría en "el hecho de que diferentes objetos puedan describirse como teniendo una característica $x$ ha de explicarse señalando que hay una entidad $x$, diferente de los objetos, tal que, sin embargo se muestra en ambos (los objetos son instancias o ejemplos de la entidad $x$ )" (Martinez, 2005:162). El realismo además se acercaría a la idea de "clases naturales" siendo éstas ahistóricas y estables, y mayormente vinculadas a los fenómenos biológicos (idea que podríamos discutir desde Butler). Por otro lado, para la postura nominalista no hay tales entidades: "lo único que existe [...] son los objetos individuales y las características de estos mismos objetos. Por lo tanto, el realismo afirma la realidad de los conceptos mientras el nominalismo la niega y los reduce a puros nombres" (Martinez, 2005:163). O aún más explícito: "Los nominalistas niegan que la naturaleza tenga trozos que despiezar. Sus oponentes replican que los nombres adecuados, las buenas descripciones de la naturaleza, despiezan la naturaleza misma en sus trozos naturales" (Hacking, 2001:141), es decir: una estructura inherente aprehensible. El "nominalismo dinámico" de Hacking, en este sentido descree de la postura realista / naturalista, y abraza la idea de que las clasificaciones se gestan en la historia por obra del entendimiento de los hombres pero que no quedan estáticas sino que sufren modificaciones a partir de la interacción con los clasificados, las matrices, y con otras clasificaciones.

Otra característica de la postura de Hacking merece ser mencionada: las clases interactivas se reconocen y se forman en el mismo momento. Es decir, el reconocimiento de la clase no se hace a partir de constatar la existencia de características comunes, como se podría dar en las clases naturales. Sino que un intento clasificatorio (que embrionariamente puede darse a partir de agrupamientos simples -heurísticos-) puede habilitar el espacio para el surgimiento de la misma. Éste último proceso puede darse por la reacción de los sujetos a la categoría o por la construcción de personas dentro de ella. Podemos criticar el uso literal de esta última proposición (y estaríamos siguiendo a Martínez [2010]), o en la misma línea ver como Hacking debe hechar mano de figuras no tan claras como "las verdades domésticas" al incluir su análisis en el tiempo.

Hemos mencionado en otro trabajo (Martínez 2009) nuestra inquietud acerca de esta caracterización de ontología histórica y nos hemos preguntado si lo que realmente quiere decir Hacking es, literalmente, que ellos no existen en ninguna forma reconocible antes de ser objetos de estudio científico 0 , más bien, que dichos objetos no son reconocibles como un objeto $X$ en tanto no es creada la clase correspondiente a los X. Una interpretación literal de sus palabras no sería consistente con los casos que él mismo propone para ilustrar su idea, al sostener por ejemplo, que el abuso infantil como práctica ha estado siempre presente aunque puede encontrarse bajo esta caracterización recién a partir de 1960. (Martinez, 2010:137) 


\section{La propuesta de Judith Butler}

Otro aporte que nos invita a pensar "lo construido" socialmente proviene de Judith Butler y de su pensamiento crítico relativo a la performatividad. En el presente documento el trabajo de ésta autora norteamericana será explorado en tres dimensiones: lo performativo como socialmente construido (que la autora trabaja en torno al género y al cuerpo), la relación de dicha construcción con la identificación/subjetivación, y la acción política-crítica que subyace a dicho enfoque.

La autora propone el uso del concepto de performatividad (al que podemos entender inicialmente como "el poder que tiene el discurso para producir aquello que nombra" por lo tanto "una esfera en la que el poder actúa como discurso" [Butler, 2002:316]) para entender las construcciones sociales relativas al género y al sexo -a la materialidad del cuerpo sexuado-. En este sentido el género se construye discursivamente en formas socio-historicamente heterogéneas al entrecruzarse con modalidades raciales, étnicas, clasísticas en distintos tiempos y regiones (Butler, 2007:49).

Veamos ésta propuesta en palabras de Butler (2007:97):

"el género es un efecto, el objeto de una investigación genealógica que delinea los factores políticos de su construcción al modo de la ontología. Afirmar que el género está construido no significa que sea ilusorio o artificial, entendiendo estos términos dentro de una relación binaria que opone lo "real" y lo "auténtico". Como una genealogía de la ontología del género, ésta explicación tiene como objeto entender la producción discursiva que hace aceptable esa relación binaria y demostrar que algunas configuraciones culturales del género ocupan el lugar de "lo real" y refuerzan e incrementan su hegemonía a través de esa feliz autonaturalización."

Y sigue (Butler, 2007:98):

"Una genealogía política de ontologías del género, si se consigue llevar a cabo, deconstruirá la apariencia sustantiva del género en sus acciones constitutivas y situará esos actos dentro de los marcos obligatorios establecidos por las diferentes fuerzas que supervisan la apariencia social del género. Revelar los actos contingentes que crean la apariencia de una necesidad naturalista -lo cual ha constituido parte de la crítica cultural por lo menos desde Marx- es un trabajo que ahora asume la carga adicional de enseñar cómo la noción misma del sujeto, inteligible sólo por su apariencia de género, permite opciones que antes habían quedado relegadas forzosamente por las diferentes reificaciones del género que han constituido sus ontologías contingentes.

Entendido así el género es una construcción social en la forma de un discurso cultural. Sin embargo es un discurso que no se opone a la materialidad. El cuerpo, en el análisis de Butler, no es mera naturaleza sometida a las formas de género culturales sino que la "naturaleza sexuada" del cuerpo es también formada por medio del discurso del género. El hecho de que se tome al cuerpo como "prediscursivo" es, según Butler (2007:55-56), también resultado de dicho discurso (una contingencia que se esconda tras la máscara de lo inevitable, en términos de 
Hacking). En este punto su planteo cobra mayor profundidad volviéndose contra los lugares comunes del feminismo: "Quienes, formados en la filosofía, siempre a cierta distancia de las cuestiones corpóreas, tratan de demarcar los terrenos corporales de esa manera descarnada inevitablemente, pasan por alto el cuerpo o, lo que es peor, escriben contra él. A veces olvidan que "el" cuerpo se presenta en géneros." (Butler, 2002:11). En este sentido, dirá Hacking (2001:29), "[Butler] rechaza la noción de que el género sea algo construido que se agrega a la identidad sexual". Éste rechazo de la "construcción" parece ser un distanciamiento con una postura feminista más amplia con respecto a las nociones de cuerpo y sujeto, sin embargo fuera de tales distinciones el planteo de Butler es de corte construccionista (en este sentido, lo construído se opone a la "natural" o "real") cómo lo deja en claro en la siguiente entrevista: "Mi tésis de la construcción social parece asustar a la gente: la idea de que el sexo es culturalmente construido. Parecen temer que estoy evacuando la noción de lo real" (Michalik:2001). Dicha postura ha sido analizado también bajo el rótulo de "constructivismo radical" (Vasterling, 1999:18).

La performatividad funciona en el plano del poder hecho discurso, y el discurso hecho carne por medio de la "repetición ritualizada de normas" (Butler, 2002:13) que funcionan como un "ideal regulatorio" (en términos de Foucault) que producen los cuerpos que gobiernan. Para la autora tanto como para Hacking, la construcción del ideal y de los sujetos que la encarnan se desarrollan juntos. Dicho planteo pone en el centro del análisis a la noción de sujeto, quién ya no tiene la capacidad de elección (voluntaria, racional e instrumental) de asumir el género, como quien decide qué atuendo ponerse a la mañana, sino se trata de un sujeto determinado por el género:

Si el género se construye a través de las relaciones de poder $y$, específicamente, las restricciones normativas que no sólo producen sino que además regulan los diversos seres corporales, ¿cómo podría hacerse derivar la instancia de esta noción de género, entendida como el efecto de la restricción productiva? Si el género no es un artificio que pueda adoptarse o rechazarse a voluntad $y$, por lo tanto, no es un efecto de la elección, ¿cómo podríamos comprender la condición constitutiva y compulsiva de las normas de género sin caer en la trampa del determinismo cultural? ¿Cómo podríamos precisamente comprender la repetición ritualizada a través de la cual esas normas producen y estabilizan no sólo los efectos del género sino también la materialidad del sexo? [...] Concebir el cuerpo como algo construido exige reconcebir la significación de la construcción misma. Y si ciertas construcciones parecen constitutivas, es decir, si tienen ese carácter de ser aquello "sin lo cual" no podríamos siquiera pensar, podemos sugerir que los cuerpos sólo surgen, sólo perduran, sólo viven dentro de las limitaciones productivas de ciertos esquemas reguladores en alto grado generizados. (Butler, 2002:12-14)

La pregunta por la performatividad se centra por la capacidad de acción del sujeto y los condicionamiento de los regímenes sexuales reguladores, específicamente en los procesos de identidad en los cuales las normas discursivas se citan formando al sujeto. La subjetivación se entiende entonces como identificación con 
una norma inalcanzable, imposible de ser asumida, y que por ello requiere que el sujeto repita constantemente este ritual identificatorio (nadie adopta un género en un sólo acto). $Y$ es en dicha identificación con la norma que el sujeto adquiere forma, es decir, que adopta el simbolismo de la norma. Dice Butler con respecto a una niña que adopta la "femeneidad":

Ésta es una "niña" que está obligada a citar la norma para que se la considere un sujeto viable y para poder conservar esa posición. De modo que la femineidad no es producto de una decisión, sino de la cita obligada de una norma, una cita cuya compleja historicidad no puede disociarse de las relaciones de disciplina, regulación y castigo. En realidad, no hay "alguien" que acate una norma de género. Por el contrario, esta cita de la norma de género es necesaria para que a uno se lo considere como "alguien", para llegar a ser "alguien" viable, ya que la formación del sujeto depende de la operación previa de las normas legitimantes de género. (Butler, 2002:326)

Sin embargo, todo simbolismo admite la resignificación. La norma ritualizada requiere de la constante repetición (del constante citado), y cada acto de repetición puede ser a la vez un acto de subversión, de apropiación y reelaboración. El hecho de que la norma sea siempre inabarcable, inagotable en el mero acto, da origen también a su debilidad. Lo simbólico es -para Butler- un proceso de regulación de la significación que varía en el tiempo. Y dicha norma funciona no sólo por la prescripción de lo general, sino también por la forclusión de lo exterior. Aquello que no se ajusta a la norma debe ser ininteligible, inhabitable, o mejor aún, invisible (Butler, 2002:47).

\section{El lugar de la crítica}

Tanto en Hacking como en Butler, el análisis de la deconstrucción crítica de las clasificaciones y de las normas involucra una actitud política frente a ellas. Hacking inicia su trabajo sobre el construccionismo social afirmando que "hablar de construcción social ha llegado a ser moneda común, algo valioso para los activistas políticos [...] Por un lado, [porque] la idea de construcción social ha sido maravillosamente liberadora. Nos recuerda, por citar un caso, que la maternidad y sus significados no son fijos e inevitables, la consecuencia de parir y crian niños. Son el producto de sucesos históricos, fuerzas sociales e ideología" (Hacking, 2001:19) si bien aclara que dichas tesis son liberadoras para aquellos que están en disposición de ser liberados. Por esto, Hacking se aparta de las concepciones de la actitud posmodernista de que "todo es construcción", actitud a la que acusa dar un uso inflacionario de la construcción, perdiendo así carácter crítico ("posmodernismo inconducente" [Retamozo, 2011:22]). El objetivo primario de los estudios construccionistas es concienciar contra el discurso de la inevitabilidad (de las categorizaciones preexistentes) por lo que se debe manifestar en reivindicaciones concretas a riesgo de volverse una moda inocua.

En lo que respecta a la crítica, el análisis de Hacking pone de relieve un asunto básico: los discursos construccionistas lidian con la ambigüedad entre el proceso y el producto. Los construccionistas argumentan que el producto no es inevitable y 
su principal fuerza radica en demostrar como se desenvolvió históricamente, es decir, en el tiempo y espacio social, haciendo foco en los aspectos contingentes de dicho proceso. La actitud construccionista es, según Hacking, "esceptica y humanista" (2002:87). Así, Hacking (2001:45-49) distingue 7 "niveles de compromiso" en relación a la crítica construccionista (caracterizada por a: proponer la inevitabilidad de lo construido; b: proponer a dicha construcción como algo malo; y c: proponer que estaríamos mejor sin ella). Estos niveles incluyen: la crítica histórica que expone el primer postulado por medio de la investigación de los orígenes contingentes de un fenómeno; la irónica que constata dicha contingencia pero que no vislumbra modos de subversión; la crítica reformista que ve a lo construido como algo negativo y que propone modificar su constitución de modo tal que pase a ser "menos malo"; la crítica desenmascaradora que no busca refutar lo construido sino socavarlo descubriendo los intereses y las funciones a las que sirve; una crítica rebelde es la que supone que nos iría mejor sin la construcción; mientras que la crítica revolucionaria es la que intenta cambiar el mundo de lo clasificado.

Rescatemos, por ahora, la critica desenmascaradora que Hacking retoma a partir de la sociología del conocimiento de Mannheim. El objetivo de ésta práctica no es negar una idea sino "determinar la función que ejerce" -deliberadamente oculta- a fin de destruir su eficacia práctica. Desenmascarar a las clases/clasificaciones humanas en tanto construcciones busca darle a los sujetos el control de su destino al permitirles hacer propias las categorías que se les aplica. La conceptualización construccionista aplicada a las ciencias sociales, y en términos de clases interactivas, responde a éste objetivo moral (Hacking, 2002:104). Así el enfoque de Hacking es explícitamente valorativo.

En la misma línea se encuentra Judith Butler quien busca desenmascarar la construcción social "del género, de las prácticas sexuales y del mismo cuerpo en un acto performativo" (Ostrovsky, 2009;6). El propósito de Butler (2002:49) es entender cómo aquello que fue excluido del discurso imperativo de la heterosexualidad (esos cuerpos que se construyen como abyectos e inhabitables), puede retornar con un efecto disruptivo que rearticulen dicho horizonte simbólico, anulando la fuerza del discurso al desarmar su inevitabilidad, pero también en función de permitir nuevas categorías que los actores sean capaces de adoptar conscientemente como propias. Así la fórmula política consiste en promover discursos cuya significación dé cuenta de un nuevo orden de valores proveniente de los sujetos clasificados (el caso queer es muestra de una reapropiación que invierte la cadena significante históricamente construida y ocultada por el poder discursivo). Dice Butler en relación al género:

Cuando tales categorías se ponen en tela de juicio, también se pone en duda la realidad del género: la frontera que separa lo real de lo irreal se desdibuja. Y es en ese momento cuando nos damos cuenta de que lo que consideramos «real», lo que invocamos como el conocimiento naturalizado del género, es, de hecho, una realidad que puede cambiar y que es posible replantear, llámese subversiva o llámese de otra forma. Aunque esta idea no constituye de por sí una revolución política, no es posible ninguna revolución política sin que se produzca un cambio 
radical en nuestra propia concepción de lo posible y lo real. En ocasiones este cambio es producto de ciertos tipos de prácticas que anteceden a su teorización explícita y que hacen que nos replanteemos nuestras categorías básicas: ¿qué es el género, cómo se produce y reproduce, y cuáles son sus opciones? (Butler, 2007:28)

En este sentido se entiende que no es posible escapar a las construcciones y a los discursos significantes, es decir, a las representaciones (Butler) o las clasificaciones (Hacking). Así dichas posturas proveen un marco teórico para la habilitación de políticas reformistas: "la labor política no es rechazar la política de representación, lo cual tampoco sería posible [...] sino sólo una genealogía crítica de sus propias acciones legitimadoras. Como tal, el punto de partida crítico es el presente histórico, como afirmó Marx. Y la tarea consiste en elaborar, dentro de este marco constituido, una crítica de las categorías de identidad que generan, naturalizan e inmovilizan las estructuras jurídicas actuales" (Butler, 2007:52) entendiendo que éste esfuerzo se enmarca en el inevitable (y democrático) fracaso de cualquier reclamo identitario que pretenda alcanzar una determinación universal y para siempre (Butler, Laclau, Zizek, 2001). Si bien dicha "inclusión total/radical" es imposible e "indeseable" (siguiendo una vez más a Vasterling [1999:33] ya que sólo la existencia de formas no hegemónicas quienes pueden introducir diferencias), se pueden tomar acciones reformistas en torno a reducir la violencia y la exclusividad con la que operan las formas hegemónicas: Invocar/usar/proponer las categorías y a la vez dejarlas abiertas a la disputa política.

\section{Una síntesis parcial}

De los autores trabajados podemos destacar los siguientes elementos en común:

1. la idea de construcción social refiere a ideales normativos-clasificatorios, y es abstracta sólo en este sentido

2. dichas ideas se generan en la interacción social en matrices y en discursos, en el tiempo y en el espacio concreto

3. en dichas matrices y discursos se forman sujetos reales, y sólo en este sentido se puede hablar de que un actor o un colectivo de actores son productos sociales

4. y sin embargo, la sujeción del actor a la categoría no es nunca completa

5. ya que las acciones de los sujetos clasificados modifican las clasificaciones, siendo la crítica un modo específico de esta interrelación

El aparato conceptual descripto nos permite pensar en los términos de una sociología de la clasificación. En lo que sigue se trabajará con un conjunto de clasificaciones específicas que intensionalmente podríamos definir cómo "clasificación de los grupos etarios" o extensionalmente como el contínuo entre "niños, adolescentes, jóvenes, adultos y mayores". En tanto sistema, se entiende que los valores de sus categorías son relacionales y que el conjunto se debe considerar abierto, o al menos, en constante reelaboración por la influencia de 
diferentes sistemas sociales, como por ejemplo la cultura o el marketing que identifican -y siguiendo a Hacking/Butler- dan origen a nuevas categorías (pensemos por ejemplo en las diferenciaciones de público que en los últimos años impuso el multimedio Disney Latino con la especialización de sus diferentes señales de televisión por cable: Disney Junior para los "preescolares", Disney XD para los "escolares menores" y Disney Channel para los "preadolescentes").

Hacking ve a las clases interactivas como el objeto de estudio propio de las ciencias sociales, mientras que a éstas clases no le opone las "naturales" sino las "indiferentes" (2001:177), es decir, aquellas clases que sin importar la ciencia en la que fueron construidas, simplemente no tienen relación con la clasificación en sí (de ahí que su propósito sea estudiar la "dinámica" de las clasificaciones). Así una sociología de la clasificación debe centrar su foco más en los mecanismos de producción de las categorías que en los elementos clasificados (y sus propiedades de distinta índole).

\section{Sobre la conceptualización sociológica de la Juventud}

En éste apartado se trabajará con la construcción conceptual/ académica de "juventud" en sociología. Los trabajos que conforman el corpus analizado (que no pretende ser exhaustivo) han sido seleccionados por ser "estados del arte" de las investigaciones en juventud, incluyendo y relevando a su vez un gran número de trabajos, existiendo muchos solapamientos de autores entre ellos: Alpízar y Bernal (2003), Chaves (2006), Dávila León (2004), Reguillo (2000), Revilla Castro (2001), Margulis y Urresti (1996).

Éstos trabajos no son análisis críticos de las construcciones sociales en tanto objeto de estudio -como por ejemplo: la construcción social de la juventud por parte de los medios de comunicación (D'Elìa y Chaves [sf]) o por parte de los docentes de escuelas nocturnas (Cuevas y Castillo [2008])- sino que llevan a cabo un análisis de carácter teórico en base a otras investigaciones. Son investigaciones de "segundo orden". Analizan los conceptos de juventud construidos a partir del análisis de la juventud de otros autores. Detallar la literatura que estos "estados del arte" están criticando excede el marco del presente ensayo. Nuestro objetivo se fundamenta en un consenso paradigmático entre los investigadores de la juventud. Proponemos que los puntos 1-5 de la síntesis anterior se encuentran saldadas en el uso corriente del concepto de "construcción social" de los investigadores del corpus trabajado. Explorar la forma específica de ésta aceveración será el objetivo de ésta parte del presente trabajo.

Varios de estos autores coinciden en que el campo de estudios en torno a la juventud ha tenido un desarrollo notable en las últimas décadas en nuestro país y en latinoamérica. Éste desarrollo se manifiesta en un creciente número de investigaciones, grupos de trabajo, comunidades y comunicaciones permitiendo cierto consenso básico sobre las temáticas y los problemas a tratar. Sostienen que la juventud en tanto una categoría que da cuenta de una construcción sociohistórica, cultural y relacional es una idea compartida en el campo de estudios mencionado. 
Se reconoce un consenso entre las investigaciones revisadas en relación a que la juventud no es algo en sí, sino que se construye en el juego de relaciones sociales. El carácter de constructo social está instalado como supuesto explícito de los trabajos provenientes de las ciencias sociales realizados desde mediados de los ochenta [...].

La aclaración de que la juventud no es una categoría definida exclusivamente por la edad y con límites fijos de carácter universal se encuentra en casi todos los textos revisados. Los autores toman precauciones para no pensar la juventud como un período fijo en el ciclo de la vida de los hombres y las mujeres, un momento universalizable, en el que todos entrarán y saldrán en el mismo momento más alla de sus condiciones objetivas de vida, su pertenencia cultural o su historia familiar. [...] El acuerdo es que si lo juvenil es una condición social, su explicación no puede estar en el "si mismo", sino que corresponde (re) construirla desde cómo es vivida y explicada por los que se condieran jóvenes y cómo es interpelada desde otros grupos de edad, desde las industrias mecánicas y desde los productos que se le ofrecen [...]. (Cháves, 2006:10)

Dávila León (2004:87-89) en su rastreo de la construcción de la noción de "adolescencia" destaca la primacía de la psicología y del desarrollo físico-mental: desde los cambios de la pubertad a la madurez reproductiva -con Stanley Hall y los psicoanalistas-, los cambios en las capacidades cognitivas -con Piaget-, y los cambios identitarios y culturales por las presiones del contexto social -con las teorías mas sociológicas-. Por su parte, la noción de "juventud" pareciera ser más propia de las humanidades de modo tal que los enfoques predominante son relativos a la construcción sociohistórica de la misma, es decir, a las condiciones sociales específicas que permiten su surgimiento y su constante redefinición (“dinamicidad y permantente evolución/involución" [Dávila León: 2004:90], una frase que pareciera endilgarle al concepto de "juventud" las características transitivas propias de un cierto discurso social sobre los jóvenes). Sin embargo, en cuanto se empieza a enumerar el carácter polisémico de la categoría asoma la pregunta: "El concepto de juventud ha adquirido innumerable significados [...]. Este concepto debe ser tratado desde la diversidad de sus sectores, donde cabría preguntarse: ¿desde dónde empezamos a construir una definición de juventud, sin que las diferencias de clases sociales y los contextos socioculturales estén sobre las identidades de las categorías de juventud?" (Dávila León, 2004:92).

Validar la primacía del uso de la categoría de juventud en términos de construcción social nos obliga a preguntarnos por aquellos fenómenos que pueden parecernos extra-sociales y que la noción de construcción nos obliga a enfrentar: en primer lugar, la incidencia de los factores biológicos-fisiológicos-psicológicos (usemos la esquiva etiqueta de "naturales") en la delimitación de la categoría; en segundo lugar, la utilización de criterios de edad y cortes etarios (entender a la edad como una categoría "natural" supone el tránsito inexorable de los sujetos a través de las categorías por medio de la mesura de un tiempo objetivo [Filardo, 2007]). Vale de antemano la respuesta de Victor Mekler (citado en Cháves [2006:11]): 
Más que un "grupo generacional" o un "estado psicosocial", la juventud es un fenómeno sociocultural en correspondencia con un conjunto de actitudes y patrones y comportamientos aceptados para sujetos de una determinada edad, en relación con la peculiar posición que ocupan en la estructura social.

Según Cháves (2006:11-15) el estudio de las edades en tanto característica fundante para las clasificaciones sociales (y con ésto la naturalización de expectativas y sentidos en torno a los grupos de edades delimitados) es descripto como "el procesamiento sociocultural de las edades" y nos remite al fenómeno de la "cronologización de la vida" que no es sólo relativo a la medición del tiempo de vida sino a la idea de que existen ciertos momentos vitales que se suceden y que coinciden en edad para distintos grupos sociales. Éstos momentos están relacionados con el tránsito por instituciones sociales como la escuela, familia, industria, etc. Solamente en ésta visión podríamos rescatar a los estudios que proponen recortes poblacionales de tipo demográficos, a fin de obviar la crítica de Margulis y Urresti (1996): "De los trabajos de tipo estadísticos no cabe esperar una mayor presición en cuanto a sus apreciaciones, ya que perscindiendo de la percepción subjetiva sacan conclusiones sobre generaciones en el papel que (como ya lo sabemos desde antiguo en nuestra práctica) no coinciden necesariamente con las generaciones en la realidad".

El concepto de "moratoria vital" (de Margulis y Urresti [1996]) es un claro ejemplo de una noción que podríamos relacionar con lo "natural" mediada por el contexto social. Dicho concepto se define en respuesta al de "moratoria social" que alude a un tiempo socialmente legítimo en que los jóvenes postergan ingresar a las responsabilidades de la vida adulta (entendida ésta como la formación de una familia propia o de adquirir compromisos a largo plazo) con el fin de formarse o experimentar previamente. Dicho concepto no sólo es adulto-centrico (la moratoria sería la permisividad para no-ser socialmente maduro) sino que muestra el caso de un "modelo" que sólo toma en consideración las posibilidades de cierta clase social, ya que es difícil pensar que jóvenes de bajos recursos económicos y sociales puedan fehacientemente escapar a tales responsabilidades. Una deconstrucción de dicho concepto tal vez nos permita constatar que fue forjado a la luz de la evidencia de la extensión del tiempo de la escolaridad y la expansión del mercado juvenil en las décadas del '50-60, fenómenos que se suelen tomar como fundacionales para la juventud mostrando que el objeto de estudio se origina con una fuerte impronta clasista. La crítica de Margulis y Urresti -por su "etnocentrismo de clase"- los lleva a definir una nueva moratoria "vital" basada en una sensación de lejanía con la muerte, la vejez y la enfermedad, es decir, como un "capital temporal" que, dadas las diferencias sociales, se puede experimentar como mayores opciones, esperanzas, y seguridades. La moratoria vital remite a un "capital (corporal) energético" cuyo desgaste (biológico) es también diferencial según la condición social. Así, lo corporal-biológico y lo cronológico-vital (siendo ésto la "materia") es mediada por lo socio-cultural (siendo ésta la "forma") -y aquí vale recordar la advertencia Hackingiana de que las matrices son tan abstractas como la categoría "joven sano" y tan materiales como las paredes de un hospitala fin de resultar en la experiencia de cada individuo. 
La pubertad es precisamente el resultado de una serie de cambios que suelen ocurrir en cierto corte cronológico al interior del proceso de desarrollo y maduración biológica de la especie. Ahora bien, estos cambios son leídos, interpretados y asumidos de manera muy particular conforme a los psiquismos de cada una de las culturas, por lo cual si bien la pubertad es un asunto de especie y por lo tanto universal, no puede decirse que las significaciones y prácticas que se realizan antes, durante y después de la pubertad son equivalentes en todos los contextos. (Patiño Torres, 2009:78)

Pensar a la juventud en tanto una categoría natural y homogénea es, siguiendo a Margulis y Urresti, un mecanismo ideológico. Por otro lado, pensar a la juventud en la contingencia requiere además dar cuenta de su heterogeneidad. La literatura trabajada consensúa en entender "las juventudes" -en plural- dadas las diferencias de formas socio-culturales (No hay razones para no pensar que éstos supuestos no se deban mantener en la construcción de otras categorias, como adultez).

Hasta aquí la construcción de las categorías, ¿qué pasa con la recepción y la reapropiación por parte de los sujetos categorizados? Revilla Castro (2001) analiza los modos en que distintos discursos científicos sobre los jóvenes penetran el ámbito extra académico (vale la aclaración de que este autor trabaja con un corpus europeo mientras que el utilizado en éste trabajo es latinoamericano y principalmente argentino) y las consecuencias que tienen en los jóvenes: "lo que se está estudiando en éstos discursos es el grado de agencialidad que hemos de conceder a la juventud como sujeto histórico y a cada joven en particular" (2001:106). Particularmente quisiéramos destacar el discurso de la juventud como producto histórico y/o social dado que es congruente con el corpus analizado. En éste discurso se da por supuesto que la juventud es un producto y que en ella se condensan los problemas sociales pero así se suele des-responsabilizar a los jóvenes, caracterizándolos como sujetos necesitados de ayuda y protección por parte de los adultos (programas de intervención social).

Sin embargo, en el corpus relevado no se han encontrado antecedentes de investigaciones que exploren las relaciones entre los discursos científicos, especialmente el discurso psico-sociológico, y su impacto en imaginarios sociales. Vale la aclaración, sin embargo, de que si se registran antecedentes de las relaciones entre los desarrollos conceptuales y ámbitos burocráticos con mayor filiación a la academia (por ejemplo, un análisis crítico del niño en tanto objeto/sujeto de derecho y las instituciones judiciales en De la Iglesia y Di lorio [2006]). Dicha tarea es apremiante especialmente en el caso de la juventud, ya que como sostiene Criado (sf), las ciencias sociales son un pilar de la matriz que sostiene y reproduce las categorías de juventud y las problemáticas juveniles.

\section{Conclusión}

Los lineamientos para el construccionismo social de lan Hacking y Judith Butler se presentan muy útiles para pensar categorías sociales como "la juventud" en la medida en que permiten interrogarnos por las relaciones entre lo normativogeneral y lo individual, haciendo las advertencias pertinentes a la especifidad de 
las ciencias sociales. Nociones como "clase interactiva" y "efecto bucle" de Hacking, y la "performatividad" de Butler proporcionan lineamientos epistemológicos claves para el análisis crítico de las clasificaciones sociales.

Por otra parte, un relevamiento bibliográfico en torno al concepto de juventud en sociología permite constatar ciertos consensos básicos entre los trabajos más paradigmáticos. Se sugiere que los desarrollos recientes en el campo mencionado siguen una línea coherente con el construccionismo social de los autores analizados. No obstante, éste desarrollo no implica que en los imaginarios sociales actuales extra-académicos no circulen concepciones naturalistas, esencialistas y/o universalistas sobre la juventud en vista de la vigencia de los análisis críticos de la construcción social. En este sentido se rescata la necesidad de explorar las relaciones entre las categorías científicas y dichos imaginarios.

\section{Excurso: Líneas de cruce entre la filosofía de lan Hacking y l a sociología de Niklas Luhmann}

La arquitectura conceptual de los sistemas sociales de Niklas Luhmann nos permitiría repensar desde otras bases la propuesta de Hacking sobre las construcciones sociales. Aquí nos limitamos a proponer -muy embrionariamente y sin ánimo de exhaustividad- algunas líneas posibles de exploración.

- El uso del concepto de de "sistemas sociales" cuya base operativa consiste en la observación-comunicación nos permite repensar las matrices en las que se generan las clasificaciones, mientras que la idea de autopoiesis puede echar luz sobre la reproducción de las clases

- Con ese marco conceptual en mente, podemos pensar en términos de auto/hetero referencia más que de agentes clasificadores y clasificados, y asì explorar aquellos casos donde los clasificados no necesariamente deban tomar conciencia de su clase (en el sentido político más estricto) para influir en las mismas. Es decir, pensar el efecto bucle no en términos de sujeto sino de reflexión sistémica. Martinez (2005:173) hace una pregunta similar: "Estamos de acuerdo en que un quark no es consciente de cómo es clasificado, pero lo que nos preguntamos es, si un niño abusado o hiperactivo lo es, como para poder afirmar con Hacking, que el efecto bucle se debe justamente a eso, a la consciencia de ser clasificado". Sin embargo, la respuesta a su inquietud se encuentra en el mismo Hacking: "Los niños autistas, por definición, tienen profundos problemas de comunicación. Entonces ¿cómo puede interactuar la clasificiación con los niños? [...] El ejemplo recalca que con interacción no me refiero sólo a la reacción autoconsciente del individuo aislado respecto a cómo se le clasifica. Me refiero, más bien, a las consecuencias que tiene ser clasificado de esa manera para el conjunto entero de individuos y las personas con las que están íntimamente relacionados" (2001:192). De todos modos, tal vez el marco luhmanniano nos permita repensar la dinámica de la producción de las clases en términos de "operaciones" y "comunicaciones" en la matriz a fin de evitarnos las dificultades del requisito de la conciencia como base de la acción. 
- Al pensar una sociedad poli-sistémica se puede plantear múltipes matrices que generan múltiples clases a las cuales nos vemos sujetos. Ésto nos habilita además a pensar el tema del riesgo en relación con las construcciones sociales y también el tema de la complejidad y el riesgo

- Podemos rescatar también la idea de "sentido" -en tanto un marco de referencia donde prima la contingencia que no llega nunca a clausurarse-. Es decir, siempre queda en el trasfondo/horizonte de la clase la marca de lo no clasificado, operando subrepticiamente sobre la categoría misma.

- Adoptar la visión cibernética de la sociedad de Luhmann nos podría ayudar a echar luz sobre cómo los productos de un sistema específico (por ejemplo, los constructos científicos) son adoptados por otros sistemas en relaciones de tipo input-output, irritación y de reproblematización bajo la mirada específica del sistema "receptor".

\section{Bibliografia}

Alpizar, L. y Bernal, M. (2003) La construcción social de las juventudes en Ultima década número 19, Cidpa Valparaiso

Birulés, F. (2008) Entrevista con Judith Butler: "El género es extramoral" Visitado el 16/08/2011 desde http://www.barcelonametropolis.cat/es/page.asp?id=21\&ui=7

Butler, J. (2002) Cuerpos que importan. Paidós: Buenos Aires

Butler, J. (2007) El género en disputa. Paidós: Buenos Aires

Butler, Laclau, Zizek (2011) Contingencia, hegemonía, universalidad : diálogos contemporáneos en la izquierda - 2da edición. Fondo de Cultura Económica: Buenos Aires

Cháves, M. (2005) Juventud negada y negativizada: Representaciones y formaciones discursivas vigentes en la Argentina contemporánea en Última década número 23. Cidpa Valparaiso. Páginas 9-32

Cháves, M. (2009) Investigaciones sobre juventudes en Argentina: estado del arte en ciencias sociales 1983-2006 en Papeles de trabajo año 5 número 2. Universidad Nacional de General San Martín. ISSN: 1851-2577. Disponible en http://www.idaes.edu.ar/papelesdetrabajo/paginas/Documentos/05_15_Informedei nvestigacion_MarianaChaves.pdf

Criado, M. (sf) Juventud en Román Reyes (Dir) Diccionario crítico de ciencias sociales. Visitado el 02/10/2011 desde http://www.ucm.es/info/eurotheo/diccionario/J/juventud.htm 
D’Elia, M.L., Cháves, M. (sf) La construcción mediática de la escuela secundaria, la juventud y los adolescentes. Ponencia en $1^{\circ}$ Encuentro sobre Jòvenes, Medios de comunicaciòn e Industrias Culturales, Facultad de periodismo de la Universidad Nacional de La Plata. Visitado el 18/07/2011 desde http://www.perio.unlp.edu.ar/observatoriodejovenes/archivos/ponencias/vinas/delia chavez.pdf

Cuevas, V., Castillo, A. (2008) Escuela media y construcción de la juventud en Revista Pilquen, Año X, Número 5. Universidad Nacional del Comahue

Dávila León, O. (2004) Adolescencia y juventud: de las nociones a los abordajes en Revista Última década número 21, Diciembre 2004, Páginas 83-104, ISSN 0718-2236

De la Iglesia, M. y Di lorio, J. (2006) La infancia institucionalizada: la práctica de la Psicología Jurídica. Determinantes Institucionales en Anuario de Investigaciones vol. 13, Ciudad de Buenos Aires. ISSN 1851-1686.

Filardo, V. (coord) (2007) La construcción social de la juventud. Documento de trabajo, producto de la investigación "Usos y apropiaciones de los espacios públicos de Montevideo y clases de edad". Departamento de Sociología Facultad de Ciencias Sociales, Grupo de estudios Urbanos y Generacionales, Disponible en http://www.geug.edu.uy/wp-content/uploads/2010/07/La-construcci\%C3\%B3nsocial-de-la-juventud_-GEUG-20071.pdf

Hacking, I. (2001) ¿La construcción social de qué? Paidós: Barcelona

Martinez, M. L. (2005) El realismo científico de lan Hacking: de los electrones a las enfermedades mentales transitorias en Redes vol.11 número 22, Universidad Nacional de Quilmes: Buenos Aires

Martinez, M. L. (2010) Ontología histórica y nominalismo dinámico: la propuesta de lan Hacking para las ciencias humanas en Cinta de Moebio número 39, páginas 130-141

Michalik, R. (2001) The desiry for Philosophy. Visitado el 01/08/2011 desde http://www.lolapress.org/elec2/artenglish/butl_e.htm

Moral Jimenez (sf) La juventud como construcción social: Análisis desde la psicología social de la adolescencia en Revista electrónica Iberoamericana de Psicologia Social (REIPS) volumen 3 número 1, Universidad de Oviedo: España. ISSN: 1576-0413. Visitado el 16/08/2011 desde http://www.psico.uniovi.es/REIPS/v3n1/art1.html

Nightingale, D., Cromby, J. (eds) (1999) Social constructionist psychology: A critical analysis of theory and practice. Open University Press: Buckingham

Ostrovsky, A. E. (2009) Epistemologìas feministas: pensando en sus aportes a la reflexión crítica de la disciplina. Ponencia presentada en el II Congreso Internacional de Investigación de la Facultad de Psicología de la Universidad Nacional de la Plata. Disponible en http://www.psico.unlp.edu.ar/segundocongreso/pdf/ejes/estudios_de_genero/016.p df 
Patiño Torres, J. F. (2009): La juventud: una construcción social-histórica de Occidente en Revista Científica Guillermo de Ockham, Vol. 7, Núm. 2, juliodiciembre, 2009, pp. 75-90. Universidad de San Buenaventura, Sede Cali, Colombia. ISSN: 1794-192X

Reguillo, R. (2007) Pensar los jóvenes. Un debate necesario en La emergencia de las culturas juveniles. Estrategias del desencanto. Bs. As.: Norma, pp. 19-48

Retamozo, M. (2011) Constructivismo: Epistemología y Metodología en las ciencias sociales. Capítulo del Tratado de Metodología de las Ciencias Sociales. México, D.F.: FCE (en Proceso de edición 2011).coordinado por Enrique de la Garza

Revilla Castro, J.C. (2001) La construcción discursiva de la juventud: lo general y lo particular en Papers : revista de sociologia. Bellaterra: Servei de Publicacions de la Universitat Autònoma de Barcelona. N. 63-64 (2001), p. 103-122 ISSN 02102862

Vasterling, V. (1999) Butler's Sophisticated Constructivism: A Critical Assessment en Hypatia, Vol. 14, No. 3 (Summer, 1999). Blackwell Publishing on behalf of Hypatia, Inc., pp. 17-38 